\title{
High Rate Performance Nanocomposite Electrode of Mesoporous Manganese Dioxide/Silver Nanowires in KI Electrolytes
}

\author{
Yanhua Jiang ${ }^{1}$, Xiuguo Cui ${ }^{1, *}$, Lei Zu ${ }^{1,2}$, Zhongkai Hu ${ }^{1,2}$, Jing Gan ${ }^{1}$, Huiqin Lian ${ }^{1,3, *}$, \\ Yang Liu ${ }^{1}$ and Guangjian Xing ${ }^{1}$
}

1 College of Materials Science \& Engineering, Beijing Institute of Petrochemical Technology, Beijing 102617, China; E-Mails: jiangyanhua@bipt.edu.cn (Y.J.); zulei@buct.edu.cn (L.Z.); huzhongkai@bipt.edu.cn (Z.H.); ganjing@bipt.edu.cn (J.G.); yang.liu@bipt.edu.cn (Y.L.); xingguangjian@bipt.edu.cn (G.X.)

2 State Key Laboratory of Organic-Inorganic Composites, Beijing University of Chemical Technology, Beijing 100029, China

3 Beijing Key Laboratory of Specialty Elastomer Composite Materials, Beijing Institute of Petrochemical Technology, Beijing 102617, China

* Authors to whom correspondence should be addressed; E-Mails: cuixiuguo@bipt.edu.cn (X.C.); lianhuiqin@bipt.edu.cn (H.L.); Tel./Fax: +86-10-812-940-07 (X.C.).

Academic Editors: Jordi Sort and Eva Pellicer

Received: 7 August 2015 / Accepted: 28 September 2015 / Published: 13 October 2015

\begin{abstract}
In recent years, manganese dioxide has become a research hotspot as an electrode material because of its low price. However, it has also become an obstacle to industrialization due to its low ratio of capacitance and the low rate performance which is caused by the poor electrical conductivity. In this study, a KI solution with electrochemical activity was innovatively applied to the electrolyte, and we systematically investigated the rate performance of the mesoporous manganese dioxide and the composite electrode with silver nanowires in supercapacitors. The results showed that when mesoporous manganese dioxide and mesoporous manganese dioxide/silver nanowires composite were used as electrodes, the strength of the current was amplified five times (from 0.1 to $0.5 \mathrm{~A} / \mathrm{g}$ ), the remaining rates of specific capacitance were 95\% (from 205.5 down to $197.1 \mathrm{~F} / \mathrm{g}$ ) and 92\% (from 208.1 down to $191.7 \mathrm{~F} / \mathrm{g}$ ) in the KI electrolyte, and the rate performance was much higher than which in an $\mathrm{Na}_{2} \mathrm{SO}_{4}$ electrolyte with a remaining rate of $25 \%$ (from 200.3 down to $49.1 \mathrm{~F} / \mathrm{g}$ ) and $60 \%$ (from 187.2 down to $113.1 \mathrm{~F} / \mathrm{g}$ ). The morphology and detail structure were investigated by Scanning electron microscopy, X-ray diffraction, Fourier transform infrared spectrometry and Nitrogen adsorption-desorption isotherms. The electrochemical performance was
\end{abstract}


assessed by cyclic voltammograms, galvanostatic charge/discharge and electrochemical impedance spectroscopy.

Keywords: mesoporous manganese dioxide; silver nanowires; electrolyte; specific capacitance

\section{Introduction}

In recent years, supercapacitors, also known as electrochemical capacitors, have become very popular as a new type of energy storage device due to their exceptional properties such as fast charge/discharge capacity, high power density, long life cycle, eco-friendliness and safety [1]. With these merits, supercapacitors have become very competitive for applications in areas such as electric hybrid vehicles, digital communication devices such as mobile phones, digital cameras, electrical tools, pulse laser techniques, and storage of energy generated by solar cells [2]. Therefore, supercapacitors perfectly fill the gap between traditional batteries and conventional capacitors [3,4]. There are two major types of supercapacitors, as categorized by their energy storage mechanism: electric double layer capacitors, and Faraday pseudo capacitors. Faraday pseudo capacitors employ Faradaic reactions occurring at the very nearly electrode interface and use electroactive materials to store energy through redox reactions $[5,6]$.

The electrode material is an important factor to directly decide the capability, delivery rates and efficiency of supercapacitors. Several transition metal oxide materials could act as effective electrode materials for supercapacitors, including ruthenium oxide, manganese dioxide $\left(\mathrm{MnO}_{2}\right)$, nickel oxide, and nickel hydroxide, among others [7]. However, some of the most capable materials are prohibitively expensive for use in commercial applications, such as ruthenium oxide and cobalt hydroxide. Recently, many researchers have focused on some cheaper metal oxides materials, such as manganese dioxide and nickel oxide, etc. [8,9]. The $\mathrm{MnO}_{2}$ has been widely studied as a supercapacitor electrode material due to its good environmental stability, high potential storage capacities and high potential window. However, due to its low electrical and ionic conductivity, its use in supercapacitors has been limited [10]. In order to overcome these limitations, mesoporous $\mathrm{MnO}_{2}$ could be prepared in a way that results in high specific surface area. Indeed, some papers have suggested that $\mathrm{MnO}_{2}$ can be combined with other highly conductive materials, such as graphene [11-14], mesoporous carbon [15,16], polyaniline [17-19] and polypyrrole [20,21] to improve the electrical conductivity. Otherwise, there are only a few previous reports related to the application of nanoporous metal/manganese dioxide based materials for supercapacitors [22].

The specific surface area of electrode materials is an important factor that can affect the electrochemical performance of supercapacitor. A larger specific surface area on an electrode will provide more electroactive sites to improve the electrochemical performance. Therefore, mesoporous $\mathrm{MnO}_{2}$ with a large specific surface area will show a better electrochemical performance than bulk. Conductivity of mesoporous $\mathrm{MnO}_{2}$ can also be increased by the addition of conductive metals. Apart from the electrode materials, the electrolyte is also particularly important in affecting the performance of supercapacitors. Some papers published in recent years have proposed that the total capacitance and energy density of supercapacitors would be greatly improved if an electrochemically-active material were added into the electrolyte [23,24]. 
In this study, a KI solution with electrochemical activity was innovatively applied into an electrolyte. Subsequently, the rate performance of the mesoporous manganese dioxide and the composite electrode with silver nanowires in supercapacitors was systematically investigated. The results showed that when mesoporous $\mathrm{MnO}_{2}$ and mesoporous $\mathrm{MnO}_{2}$ /silver nanowires were composited as an electrode, the strength of the current was amplified 5 times (from 0.1 to $0.5 \mathrm{~A} / \mathrm{g}$ ), the remain rates of specific capacitance were $95 \%$ and $92 \%$ in the KI electrolyte, and the rate performance were much higher than a $\mathrm{Na}_{2} \mathrm{SO}_{4}$ electrolyte, where the remain rate were $25 \%$ and $60 \%$. Results indicate that KI electrolytes may become a new mode for supercapacitors to change their specific capacitance.

\section{Results and Discussion}

\subsection{Effect of the Amount of Acid on the Structure of $\mathrm{MnO}_{2}$}

Because potassium permanganate is a strong oxidizing agent and ethylene glycol is a strong reducing agent, the exothermic redox reaction between the two of them leads to the formation of $\mathrm{MnO}_{2}$ and other oxidized products, such as aldehydes or a mixture of aldehydes, carboxylic acids and even $\mathrm{CO}_{2}$. The formation process may be explained as follows: Once the ethylene glycol was added into the $\mathrm{KMnO}_{4}$ acid solution, $\mathrm{MnO}_{2}$ nuclei were formed immediately, which acted as the precursor. Concentrated sulfuric acid was then added in the solution, increasing the oxidizability of the potassium permanganate and further increasing the reaction rate. On the other hand, acid can also "etch" the originally produced $\mathrm{MnO}_{2}$, thereby increase the specific surface area. However, adding an excess of acid could not increase of surface area correspondingly, because if the acid concentration is too high, the oxidation of potassium permanganate would become stronger and the reaction rate was further increased, the originally produced $\mathrm{MnO}_{2}$ nuclei was too late to be etched, so the regeneration ability also cannot continue [25].

The samples of $\mathrm{MnO}_{2}-2, \mathrm{MnO}_{2}-4, \mathrm{MnO}_{2}-5, \mathrm{MnO}_{2}-7$ were prepared by adding 2, 4, 5 and $7 \mathrm{~mL}$ of concentrated sulfuric acid into the reaction conditions, respectively. The BET surface areas of the samples were 204.41, 232.96, 203.54 and $175.57 \mathrm{~m}^{2} / \mathrm{g}$, respectively, and the pore diameters of the samples were 5.31, 3.64, 3.90 and $5.71 \mathrm{~nm}$, respectively. As can be seen in Figure 1, all of the isotherms were type IV and displayed hysteresis loops in the relative pressure range of 0.6-0.9. Furthermore, a plateau appeared in the adsorption branch, suggesting that all of the samples were mesoporous. However, the nitrogen sorption isotherm of $\mathrm{MnO}_{2}-4$ exhibited a hysteresis loop in the relative pressure range of 0.4-0.7 and the pore diameter was the smallest among all samples. This conclusion indicates that the mesoporous structure of $\mathrm{MnO}_{2}-4$ was more uniform than the others, so the $\mathrm{MnO}_{2}-4$ was used for the preparation of the composite materials. 


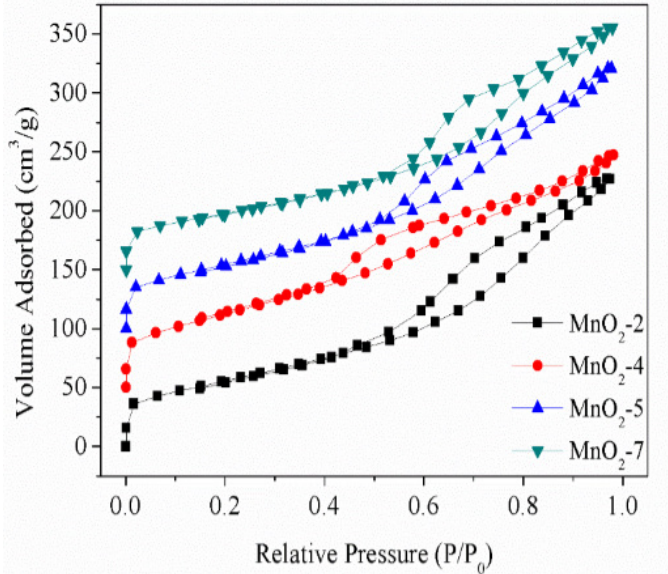

(a)

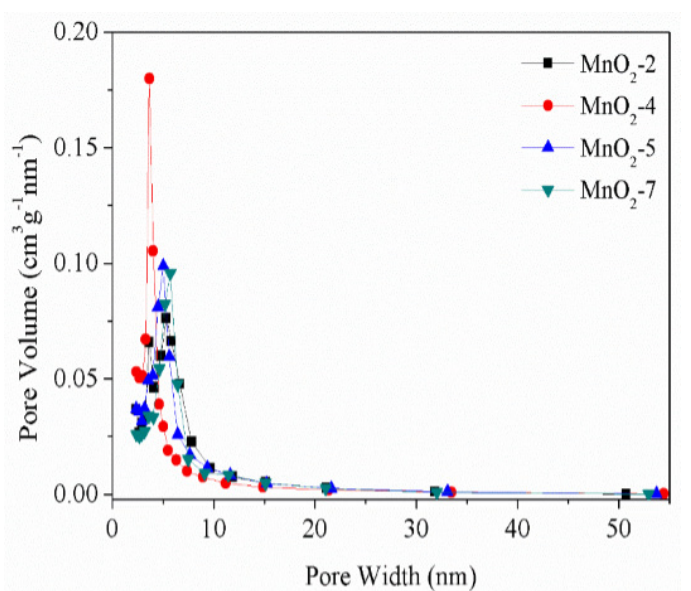

(b)

Figure 1. Nitrogen adsorption/desorption isotherms and BJH pore-size distribution curves of the samples $\mathrm{MnO}_{2}-2, \mathrm{MnO}_{2}-4, \mathrm{MnO}_{2}-5, \mathrm{MnO}_{2}-7$. (a) Nitrogen adsorption/desorption isotherms; (b) Pore-size distribution curves.

\subsection{Microstructure Characterization}

Figure 2 shows the scanning electron microscopy (SEM) images of mesoporous $\mathrm{MnO}_{2}$ and mesoporous $\mathrm{MnO}_{2}$ /silver nanowires nanocomposite. As shown in Figure 2a, the mesoporous $\mathrm{MnO}_{2}$ has a uniform particle morphology. And in Figure 2b, the mesoporous $\mathrm{MnO}_{2}$ and the silver nanowires have dispersed uniformly, which provide a chance to improve the electrochemical performance of supercapacitors.

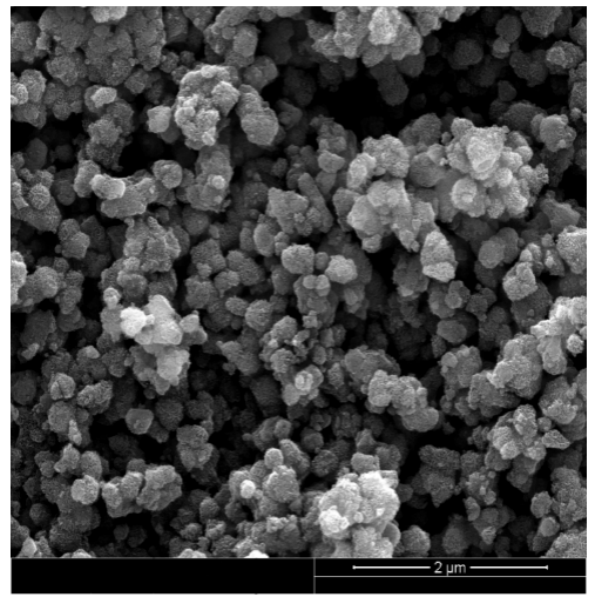

(a)

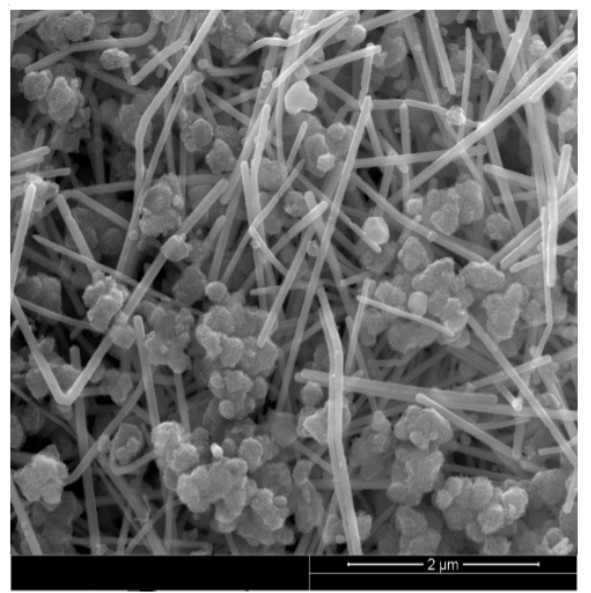

(b)

Figure 2. Scanning electron microscopy (SEM) images of mesoporous $\mathrm{MnO}_{2}$, mesoporous $\mathrm{MnO}_{2} /$ silver nanowires. (a) Mesoporous $\mathrm{MnO}_{2}$; (b) Mesoporous $\mathrm{MnO}_{2} /$ silver nanowires.

Figure 3a depicted the X-ray diffraction (XRD) pattern of the as-prepared mesoporous $\mathrm{MnO}_{2}$, silver nanowires and mesoporous $\mathrm{MnO}_{2} /$ silver nanowires. As shown in Figure 3a, the main diffraction peaks at $2 \theta=35.6^{\circ}$ and $63.8^{\circ}$ in the as-prepared mesoporous $\mathrm{MnO}_{2}$, the diffraction angles at $38.2^{\circ}, 44.5^{\circ}, 64.5^{\circ}$ and $77.2^{\circ}$ in the as-prepared silver nanowires, all the reflections can be indexed to the face centered cubic structure according to the previous published papers [26,27]. In contrast with the as-prepared silver 
nanowires, the diffraction peaks at $38.2^{\circ}, 44.5^{\circ}, 64.5^{\circ}$ and $77.2^{\circ}$ also existed in the mesoporous $\mathrm{MnO}_{2} /$ silver nanowires; moreover, the diffraction angles at $35.6^{\circ}$ which respected the mesoporous $\mathrm{MnO}_{2}$ crystalline phase caused a slight shift to occur, and set the diffraction angles at $30.1^{\circ}$.

To obtain more specific information about the as-prepared mesoporous $\mathrm{MnO}_{2} /$ silver nanowires, Fourier transform infrared spectrometry (FT-IR) spectra of the mesoporous $\mathrm{MnO}_{2}$, silver nanowires and the composite were obtained. As seen from Figure 3b, the spectrum of $\mathrm{MnO}_{2}$ shows a broad absorption band at $3424 \mathrm{~cm}^{-1}$, which can be assigned to the $\mathrm{O}-\mathrm{H}$ stretching vibration, and the peak at $532 \mathrm{~cm}^{-1}$ should be ascribed to the contribution of the $\mathrm{Mn}-\mathrm{O}$ vibrations, while other three pronounced peaks centered at 1081, 1384 and $1620 \mathrm{~cm}^{-1}$ are $\mathrm{O}-\mathrm{H}$ stretching vibrations on $\mathrm{Mn}$ atom. In contrast with the mesoporous $\mathrm{MnO}_{2}$, the typical $\mathrm{O}-\mathrm{H}$ absorption bands at about 3000, 1620, 1081 and $589 \mathrm{~cm}^{-1}$ for the mesoporous $\mathrm{MnO}_{2} /$ silver nanowires almost appear, moreover, the peaks at 2322, 2033 and $1641 \mathrm{~cm}^{-1}$ of the as-prepared silver nanowires belong to bending mode of hydroxyl groups and carbonyl groups, respectively, are still observed, suggesting that the addition of the silver nanowires modified the groups on the surface of the $\mathrm{MnO}_{2}[28]$.

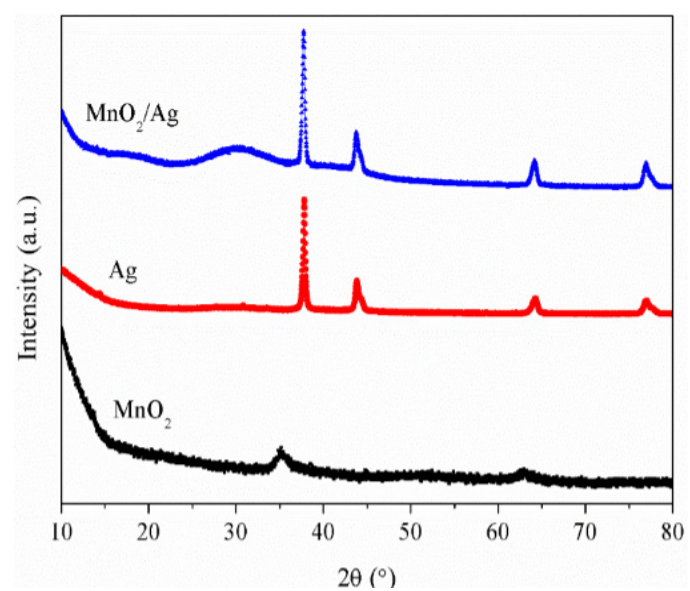

(a)

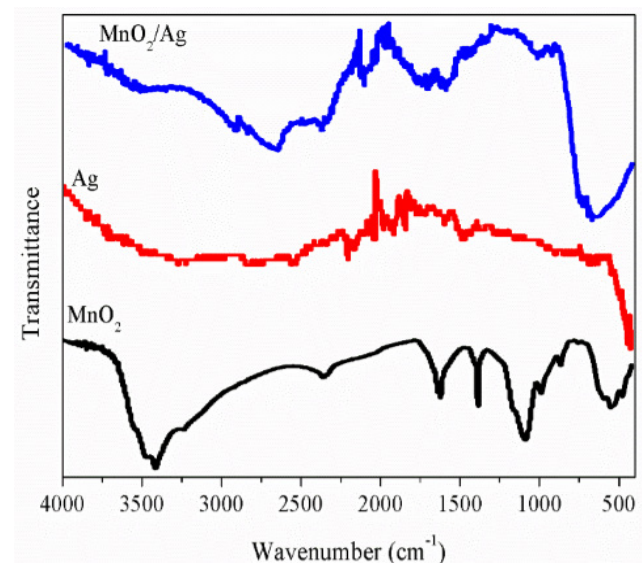

(b)

Figure 3. (a) X-ray diffraction (XRD) spectra of mesoporous $\mathrm{MnO}_{2}$, silver nanowires and mesoporous $\mathrm{MnO}_{2} /$ silver nanowires; (b) Fourier transform infrared spectrometry (FT-IR) spectra of mesoporous $\mathrm{MnO}_{2}$, silver nanowires and mesoporous $\mathrm{MnO}_{2} /$ silver nanowires.

\subsection{Electrochemical Characterizations}

As is well-known, silver is an excellent electronic conductor, and it has been used to dope electrode materials to improve their electrochemical performance in the past. The detail conductivity data of the samples are shown in Table 1. The chart shows that silver can change the electrical resistivity and electrical conductivity of mesoporous $\mathrm{MnO}_{2}-4$, and with an increase to the added amount of the silver, the electrical resistivity of the sample decreases and the electrical conductivity increases. Therefore, in the following tests of the electrical performance, a sample of $\mathrm{MnO}_{2}: \mathrm{Ag}=1: 1$ was used.

To evaluate the potential applications as an electrode material for supercapacitors, the electrochemical properties of the mesoporous $\mathrm{MnO}_{2}$-based electrode material were investigated in a three-electrode system in $0.5 \mathrm{M} \mathrm{Na}_{2} \mathrm{SO}_{4}$ and firstly studied in $0.1 \mathrm{M}, 0.2 \mathrm{M}$ and $0.5 \mathrm{M}$ KI electrolyte (Table 2). Some 
of the reported data beat the performance of the present paper, but KI electrolyte was studied in the first, and it may become a new area for supercapacitors to change the specific capacitance.

Table 1. The detail electrical resistivity (ER) and electrical conductivity (EC) of mesoporous $\mathrm{MnO}_{2}$ and manganese dioxide-based composite under different experimental conditions.

\begin{tabular}{ccc}
\hline Sample & ER $(\boldsymbol{\Omega} \cdot \mathbf{c m})$ & EC $(\mathbf{S} / \mathbf{c m})$ \\
\hline $\mathrm{MnO}_{2}-4$ & $2.54 \times 10^{6}$ & $3.94 \times 10^{-7}$ \\
$\mathrm{Ag}$ & $1.73 \times 10^{-2}$ & $5.78 \times 10$ \\
$\mathrm{MnO}_{2}: \mathrm{Ag}=1: 0.25$ & $4.33 \times 10^{4}$ & $2.31 \times 10^{-5}$ \\
$\mathrm{MnO}_{2}: \mathrm{Ag}=1: 0.5$ & $1.10 \times 10^{2}$ & $9.10 \times 10^{-3}$ \\
$\mathrm{MnO}_{2}: \mathrm{Ag}=1: 1$ & 8.37 & $1.19 \times 10^{-1}$ \\
\hline
\end{tabular}

Table 2. Comparison of specific capacitances of the reported $\mathrm{MnO}_{2}$-based electrodes and the present work. All values are measured using the three-electrode system.

\begin{tabular}{|c|c|c|c|c|}
\hline Samples & $\operatorname{Cs}\left(F \cdot g^{-1}\right)$ & Electrolyte & Test Condition & References \\
\hline Ambigel $\mathrm{MnO}_{2}$ & 130 & $2 \mathrm{M} \mathrm{NaCl}$ & $5 \mathrm{mV} \cdot \mathrm{s}^{-1}$ & [29] \\
\hline$\alpha-\mathrm{MnO}_{2}$ nanorod & 152 & $1 \mathrm{M} \mathrm{Na}_{2} \mathrm{SO}_{4}$ & $5 \mathrm{mV} \cdot \mathrm{s}^{-1}$ & [30] \\
\hline Birnessite hollow $\mathrm{MnO}_{2}$ & 169 & $1 \mathrm{M} \mathrm{Na}_{2} \mathrm{SO}_{4}$ & $0.25 \mathrm{~A} \cdot \mathrm{g}^{-1}$ & [31] \\
\hline $\mathrm{MnO}_{2}$ spherical particle & 170.8 & $0.5 \mathrm{M} \mathrm{K}_{2} \mathrm{SO}_{4}$ & $0.5 \mathrm{~A} \cdot \mathrm{g}^{-1}$ & [32] \\
\hline $\mathrm{MnO}_{2}$ nanowire & 176 & $1 \mathrm{M} \mathrm{Na}_{2} \mathrm{SO}_{4}$ & $5 \mathrm{mV} \cdot \mathrm{s}^{-1}$ & [33] \\
\hline $\mathrm{MnO}_{2}$ nano hollow sphere & 178 & $0.5 \mathrm{M} \mathrm{K}_{2} \mathrm{SO}_{4}$ & $0.5 \mathrm{~A} \cdot \mathrm{g}^{-1}$ & [34] \\
\hline Porous $\mathrm{MnO}_{2}$ nanoparticle & 178.9 & $1 \mathrm{M} \mathrm{Na}_{2} \mathrm{SO}_{4}$ & $1 \mathrm{mV} \cdot \mathrm{s}^{-1}$ & [35] \\
\hline $\mathrm{MnO}_{2}$ particle & 180 & $0.5 \mathrm{M} \mathrm{KOH}$ & $1 \mathrm{mV} \cdot \mathrm{s}^{-1}$ & [36] \\
\hline Porous nano- $\mathrm{MnO}_{2}$ & 198.1 & $1 \mathrm{M} \mathrm{Na}_{2} \mathrm{SO}_{4}$ & $0.28 \mathrm{~A} \cdot \mathrm{g}^{-1}$ & [37] \\
\hline $\mathrm{MnO}_{2}$ nanoparticle & 200 & $0.2 \mathrm{M} \mathrm{K}_{2} \mathrm{SO}_{4}$ & $5 \mathrm{mV} \cdot \mathrm{s}^{-1}$ & [38] \\
\hline $\mathrm{MnO}_{2}$ nanowisker & 200 & $1 \mathrm{M} \mathrm{Na}_{2} \mathrm{SO}_{4}$ & $2 \mathrm{mV} \cdot \mathrm{s}^{-1}$ & [39] \\
\hline Amorphous $\mathrm{MnO}_{2} \cdot n \mathrm{H}_{2} \mathrm{O}$ & 200 & $2 \mathrm{M} \mathrm{KCl}$ & $5 \mathrm{mV} \cdot \mathrm{s}^{-1}$ & [40] \\
\hline $\mathrm{MnO}_{2}$ nanosheet array & 201 & $1 \mathrm{M} \mathrm{Na}_{2} \mathrm{SO}_{4}$ & $1 \mathrm{~A} \cdot \mathrm{g}^{-11}$ & [41] \\
\hline Birnessite $\mathrm{MnO}_{2}$ nanosphere & 210 & $1 \mathrm{M} \mathrm{Na}_{2} \mathrm{SO}_{4}$ & $1 \mathrm{~A} \cdot \mathrm{g}^{-1}$ & [42] \\
\hline Coral-like $\mathrm{MnO}_{2}$ & 221 & $1 \mathrm{M} \mathrm{Na}_{2} \mathrm{SO}_{4}$ & $0.5 \mathrm{~A} \cdot \mathrm{g}^{-1}$ & [43] \\
\hline $\mathrm{MnO}_{2}$ thin sheet & 230 & $0.5 \mathrm{M} \mathrm{Na}_{2} \mathrm{SO}_{4}$ & $20 \mathrm{mV} \cdot \mathrm{s}^{-1}$ & [44] \\
\hline$\gamma-\mathrm{MnO}_{2}$ film & 240 & $0.1 \mathrm{M} \mathrm{Na}_{2} \mathrm{SO}_{4}$ & $1 \mathrm{~mA} \cdot \mathrm{cm}^{-2}$ & [45] \\
\hline Lamellar $\mathrm{MnO}_{2}$ & 242.1 & $2 \mathrm{M} \mathrm{NH}_{4}\left(\mathrm{SO}_{4}\right)_{2}$ & $2 \mathrm{~mA} \cdot \mathrm{cm}^{-2}$ & [46] \\
\hline$\alpha-\mathrm{MnO}_{2}$ nanorod & 245 & $1 \mathrm{M} \mathrm{KOH}$ & $1 \mathrm{Ag}^{-1}$ & [47] \\
\hline Amorphous $\mathrm{MnO}_{2}$ particle & 251 & $1 \mathrm{M} \mathrm{Na}_{2} \mathrm{SO}_{4}$ & $2 \mathrm{mV} \cdot \mathrm{s}^{-1}$ & [48] \\
\hline Mesoporous $\mathrm{MnO}_{2}$ & 200.3 & $0.5 \mathrm{M} \mathrm{Na}_{2} \mathrm{SO}_{4}$ & $0.1 \mathrm{~A} \cdot \mathrm{g}^{-1}$ & This work \\
\hline Mesoporous $\mathrm{MnO}_{2}$ & 205.2 & $0.5 \mathrm{M} \mathrm{KI}$ & $0.1 \mathrm{~A} \cdot \mathrm{g}^{-1}$ & This work \\
\hline Mesoporous $\mathrm{MnO}_{2}$ & 200.6 & $0.5 \mathrm{M} \mathrm{KI}$ & $0.2 \mathrm{~A} \cdot \mathrm{g}^{-1}$ & This work \\
\hline Mesoporous $\mathrm{MnO}_{2}$ & 197.1 & $0.5 \mathrm{M} \mathrm{KI}$ & $0.5 \mathrm{~A} \cdot \mathrm{g}^{-1}$ & This work \\
\hline $\mathrm{Ag} / \mathrm{Mesoporous} \mathrm{MnO}_{2}$ & 187.2 & $0.5 \mathrm{M} \mathrm{Na}_{2} \mathrm{SO}_{4}$ & $0.1 \mathrm{~A} \cdot \mathrm{g}^{-1}$ & This work \\
\hline $\mathrm{Ag} / \mathrm{Mesoporous} \mathrm{MnO}_{2}$ & 208.1 & $0.2 \mathrm{M} \mathrm{KI}$ & $0.1 \mathrm{~A} \cdot \mathrm{g}^{-1}$ & This work \\
\hline $\mathrm{Ag} / \mathrm{Mesoporous} \mathrm{MnO}_{2}$ & 200.5 & $0.2 \mathrm{M} \mathrm{KI}$ & $0.2 \mathrm{~A} \cdot \mathrm{g}^{-1}$ & This work \\
\hline $\mathrm{Ag} / \mathrm{Mesoporous} \mathrm{MnO}_{2}$ & 191.7 & $0.2 \mathrm{M} \mathrm{KI}$ & $0.5 \mathrm{~A} \cdot \mathrm{g}^{-1}$ & This work \\
\hline
\end{tabular}

Figure 4a shows the $\mathrm{CV}$ curves of the mesoporous $\mathrm{MnO}_{2}$ electrode at a scan rate of $5 \mathrm{mV} / \mathrm{s}$ in different aqueous electrolytes $\left(0.5 \mathrm{M} \mathrm{Na}_{2} \mathrm{SO}_{4}, 0.1 \mathrm{M}, 0.2 \mathrm{M}\right.$ and $\left.0.5 \mathrm{M} \cdot \mathrm{KI}\right)$ in the range of $-0.3-0.7 \mathrm{~V}$. It is clear 
that the $\mathrm{CV}$ curve of mesoporous $\mathrm{MnO}_{2}$ in $0.5 \mathrm{M} \mathrm{Na}_{2} \mathrm{SO}_{4}$ has no redox peaks over the potential range. The shape of the $\mathrm{CV}$ shows an approximate rectangular mirror image characteristic of capacitive behavior. This may be explained by the fact that mesoporous $\mathrm{MnO}_{2}$ occurred redox reaction in each potential. Therefore, there are generally no particularly prominent redox peaks in the CV curves. However, when the conductive of the electrode material is good and the scan rate is low, the cation can not only undertake the redox reaction on the surface, it is also possible carry out the redox reaction in the channels. In that case, obvious redox peaks will appear. Additionally, specific redox peaks have appeared in the CV curves of mesoporous manganese dioxide in KI electrolyte. The possible redox reaction of $\mathrm{I}^{-}$at the electrode/electrolyte interface can be expressed as shown in Equation (1-4) [49-51]. These redox reactions may be the reasons that a higher specific capacitance of the electrode materials occurs $\mathrm{KI}$ than in $\mathrm{Na}_{2} \mathrm{SO}_{4}$ electrolyte.

$$
\begin{aligned}
& 3 \mathrm{I}^{-} \leftrightarrow \mathrm{I}^{-}{ }_{3}+2 \mathrm{e}^{-} \\
& 2 \mathrm{I}^{-} \leftrightarrow \mathrm{I}^{-}{ }_{2}+2 \mathrm{e}^{-} \\
& 2 \mathrm{I}^{-} \leftrightarrow 3 \mathrm{I}^{-}{ }_{3}+2 \mathrm{e}^{-} \\
& \mathrm{I}_{2}+6 \mathrm{H}_{2} \mathrm{O} \leftrightarrow 2 \mathrm{IO}_{3}{ }^{-}+12 \mathrm{H}^{+}+10 \mathrm{e}^{-}
\end{aligned}
$$

Figure $4 \mathrm{~b}$ presents the charge/discharge curves of mesoporous $\mathrm{MnO}_{2}$ at the experimental condition of $0.2 \mathrm{~A} / \mathrm{g}$ in $0.1,0.2$ and $0.5 \mathrm{M} \mathrm{KI}$ electrolyte in the range of $0-0.30 \mathrm{~V}$. It can be seen that with the increase of the concentration of $\mathrm{I}^{-}$, the capacitance of the mesoporous $\mathrm{MnO}_{2}$ electrode also increases. All of the specific capacitance of the mesoporous $\mathrm{MnO}_{2}$ in the $\mathrm{KI}$ electrolyte are higher than those in the $\mathrm{Na}_{2} \mathrm{SO}_{4}$ electrolyte. Figure $4 \mathrm{c}$ shows the charge/discharge curves of the mesoporous $\mathrm{MnO}_{2}$ electrode measured at different current densities $(0.1,0.2$ and $0.5 \mathrm{~A} / \mathrm{g})$ in $0.5 \mathrm{M} \mathrm{KI}$ electrolyte. From the detailed data shown in Table 3, it is clear that the mesoporous $\mathrm{MnO}_{2}$ electrode material has a high rate of specific capacitance in $0.5 \mathrm{M} \mathrm{KI}$ electrolyte. Electrochemical impedance spectroscopy (EIS) measurements were taken to study the storage kinetics of all of the as-prepared materials. As shown in Figure 4d, the EIS of all samples was composed of a partially overlapped semicircle and a straight sloping line. Additionally, the diameter of the semicircle is related to the resistance of the electrode materials. As the diameter decreased, so did the resistance. It was found that the resistance of the electrode materials was the smallest in the $0.5 \mathrm{M} \mathrm{KI}$ electrolyte. This is related to the previous discussion.

Figure 5a shows the $\mathrm{CV}$ curves of the mesoporous $\mathrm{MnO}_{2} /$ silver nanowires electrodes at a scan rate of $5 \mathrm{mV} / \mathrm{s}$ in different aqueous electrolytes $\left(0.5 \mathrm{M} \mathrm{Na}_{2} \mathrm{SO}_{4}, 0.1 \mathrm{M}, 0.2 \mathrm{M}\right.$ and $\left.0.5 \mathrm{M} \mathrm{KI}\right)$ in the range of $-0.3-0.7 \mathrm{~V}$. It can be seen that the $\mathrm{CV}$ curve of the mesoporous $\mathrm{MnO}_{2} /$ silver nanowires in $0.5 \mathrm{M} \mathrm{Na}_{2} \mathrm{SO}_{4}$ has redox peaks appeared over the potential range. However, the area of the $\mathrm{CV}$ curve of the mesoporous $\mathrm{MnO}_{2} /$ silver nanowires in $0.5 \mathrm{M} \mathrm{Na}_{2} \mathrm{SO}_{4}$ was obviously smaller than that of the other $\mathrm{CV}$ curves, which reflects the fact that the specific capacitance of the mesoporous $\mathrm{MnO}_{2} /$ silver nanowires in $0.5 \mathrm{M} \mathrm{Na}_{2} \mathrm{SO}_{4}$ electrolyte was smaller than the specific capacitance of the mesoporous $\mathrm{MnO}_{2} /$ silver nanowires in $\mathrm{KI}$ electrolyte. Figure $5 \mathrm{~b}$ presents the charge/discharge curves of the mesoporous $\mathrm{MnO}_{2} /$ silver nanowires composite electrode at the experimental condition of $0.5 \mathrm{~A} / \mathrm{g}$ in $0.1,0.2$ and $0.5 \mathrm{M}$ KI electrolyte in the range of $0-0.35 \mathrm{~V}$. For the pure $\mathrm{MnO}_{2}$, the large Warburg region indicates great variation in the ion diffusion path lengths and an increase of ion movement obstruction in the process of ion diffusion into the interior of the electrode. This implies that silver nanowire dopant in $\mathrm{MnO}_{2}$ can promote the ion diffusion rate, which explains the fast current response in the $\mathrm{CV}$ curve and the ideal capacitive behavior 
of the mesoporous $\mathrm{MnO}_{2}$ /silver nanowires composite electrode. Obviously, the charge/discharge curve results confirm that the silver nanowires dopant in $\mathrm{MnO}_{2}$ not only enhances the electron transfer efficiency but also facilitates ion diffusion [52-54]. Additionally, due to the synergistic effect of the electrical conductivity of the electrode and the electrolyte, the specific capacitance of the mesoporous $\mathrm{MnO}_{2} /$ silver nanowires reaches its maximum in $0.2 \mathrm{M} \mathrm{KI}$ electrolyte. Figure $5 \mathrm{c}$ presents the charge/discharge curves of the mesoporous $\mathrm{MnO}_{2} /$ silver nanowires composite electrode with different current densities in $0.2 \mathrm{M} \mathrm{KI}$ in the range of $0-0.35 \mathrm{~V}$. It is clear that with an increase of the current density, the charge/discharge voltage also increases, and a larger voltage drop appeared. These results imply that the changing test conditions also affected the concentration of iodine ions in the electrode surface and the electrolyte. As shown in Figure 5d, the EIS of all of the samples was composed of a partially overlapped semicircle and a straight sloping line. It is noted that for all samples, at very high frequency, the intercepts at real part Z' were almost the same, indicating the same combination resistance of ionic resistance of electrolyte, intrinsic resistance of active materials and contact resistance at the active material/current collector interface $[55,56]$.

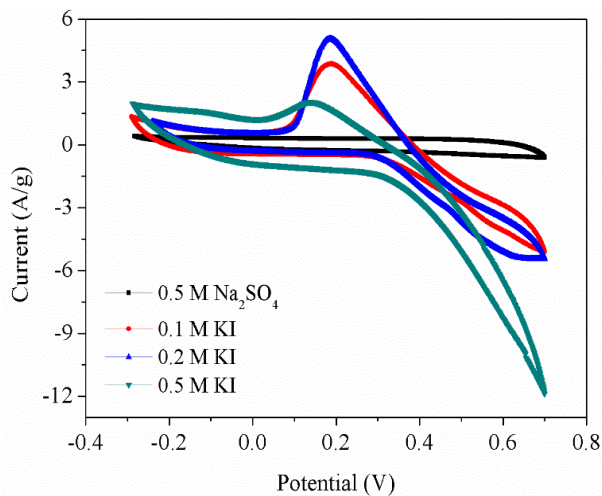

(a)

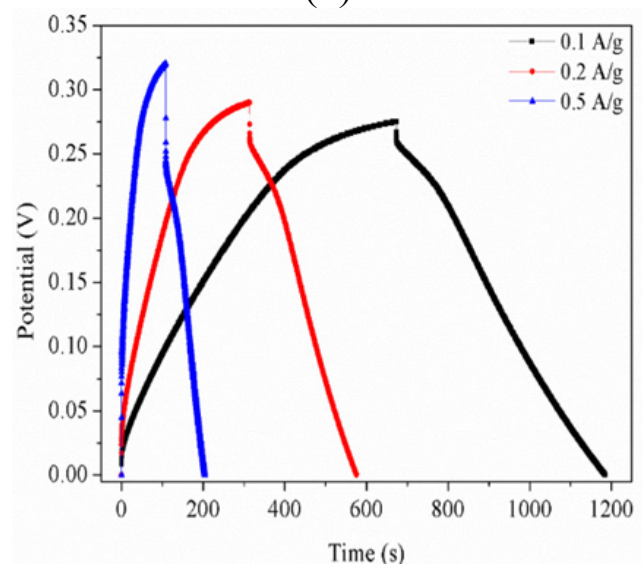

(c)

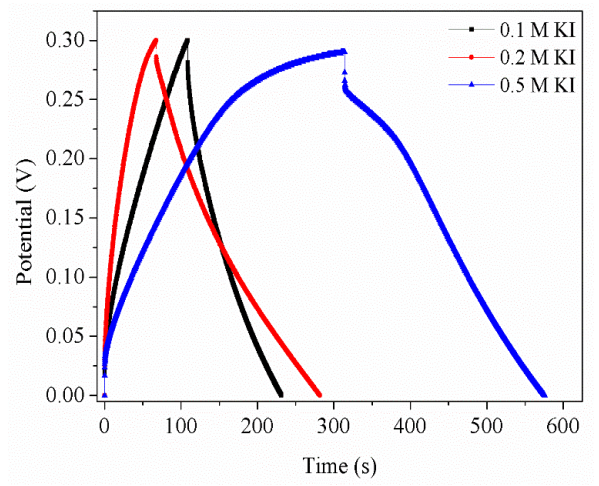

(b)

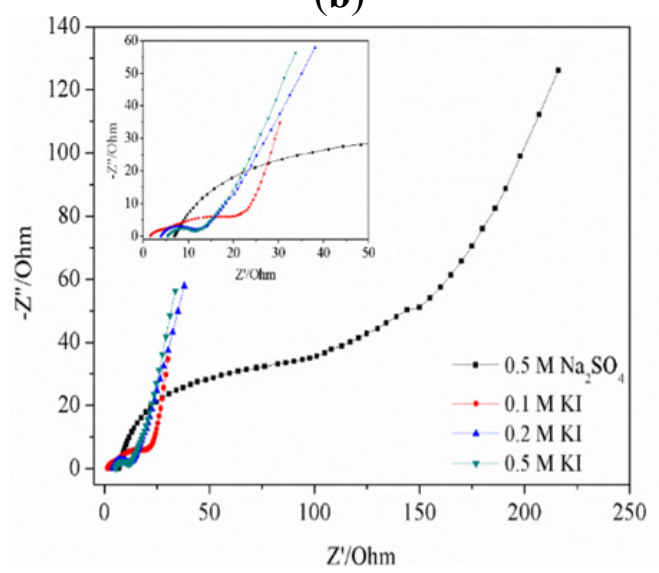

(d)

Figure 4. (a) cyclic voltammograms (CV) curves of mesoporous $\mathrm{MnO}_{2}$ at $5 \mathrm{mV} / \mathrm{s}$ in $0.5 \mathrm{M}$ $\mathrm{Na}_{2} \mathrm{SO}_{4}, 0.1 \mathrm{M}, 0.2 \mathrm{M}$ and $0.5 \mathrm{M}$ KI electrolyte; (b) Galvanostatic charge/discharge curves of mesoporous $\mathrm{MnO}_{2}$ at $0.2 \mathrm{~A} / \mathrm{g}$ in different molar concentration $(0.1 \mathrm{M}, 0.2 \mathrm{M}$ and $0.5 \mathrm{M})$ $\mathrm{KI}$ electrolyte; (c) Galvanostatic charge/discharge curves of mesoporous $\mathrm{MnO}_{2}$ at $0.1,0.2$ and $0.5 \mathrm{~A} / \mathrm{g}$ in $0.5 \mathrm{M} \mathrm{Na}_{2} \mathrm{SO}_{4}$ electrolyte; (d) Electrochemical impedance spectroscopy curves of mesoporous $\mathrm{MnO}_{2}$ in $0.5 \mathrm{M} \mathrm{Na}_{2} \mathrm{SO}_{4}$ and $0.1,0.2$ and $0.5 \mathrm{M}$ KI electrolyte. 


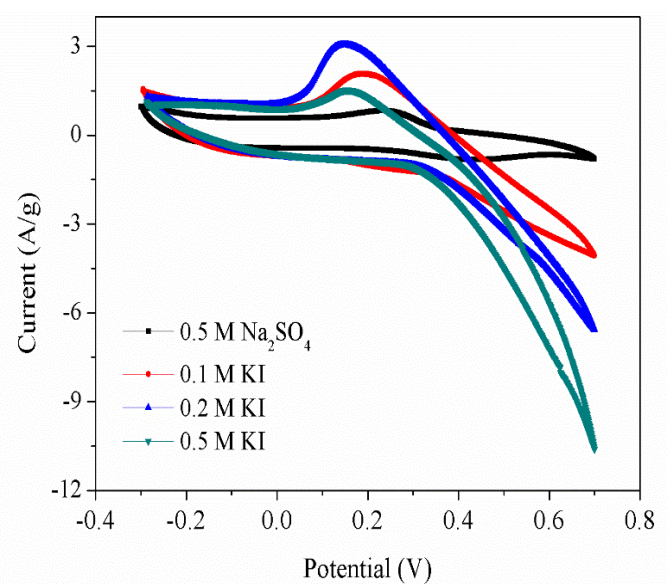

(a)

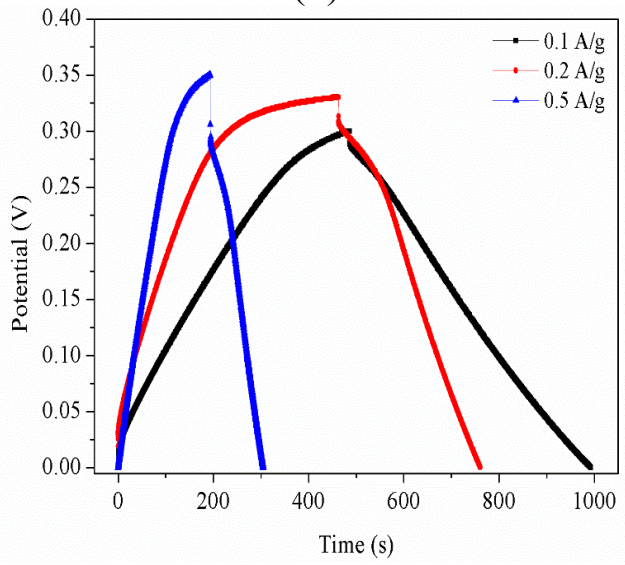

(c)

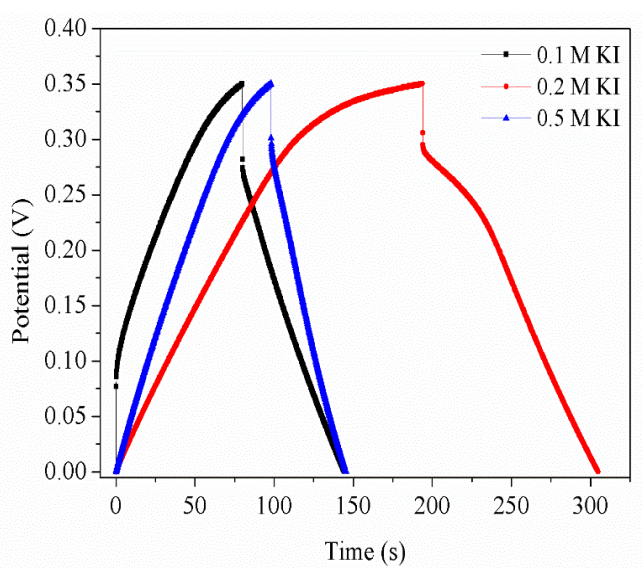

(b)

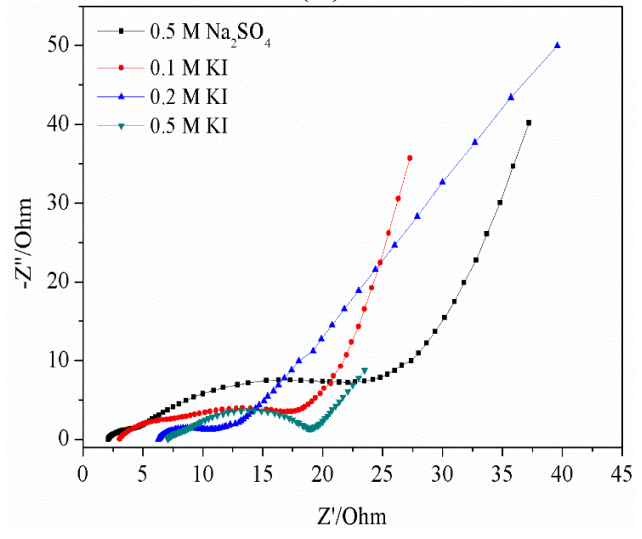

(d)

Figure 5. (a) $\mathrm{CV}$ curves of mesoporous $\mathrm{MnO}_{2} /$ silver nanowires at $5 \mathrm{mV} / \mathrm{s}$ in $0.5 \mathrm{M} \mathrm{Na}_{2} \mathrm{SO}_{4}$, $0.1 \mathrm{M}, 0.2 \mathrm{M}$ and $0.5 \mathrm{M}$ KI electrolyte; (b) Galvanostatic charge/discharge curves of mesoporous $\mathrm{MnO}_{2} /$ silver nanowires at $0.2 \mathrm{~A} / \mathrm{g}$ in different molar concentration $(0.1 \mathrm{M}$, $0.2 \mathrm{M}$ and $0.5 \mathrm{M}$ ) KI electrolyte; (c) Galvanostatic charge/discharge curves of mesoporous $\mathrm{MnO}_{2} /$ silver nanowires at $0.1,0.2$ and $0.5 \mathrm{~A} / \mathrm{g}$ in $0.5 \mathrm{M} \mathrm{Na}_{2} \mathrm{SO}_{4}$ electrolyte; (d) Electrochemical impedance spectroscopy curves of mesoporous $\mathrm{MnO}_{2} /$ silver nanowires in $0.5 \mathrm{M} \mathrm{Na}_{2} \mathrm{SO}_{4}$ and $0.1,0.2$ and $0.5 \mathrm{M} \mathrm{KI}$ electrolyte.

All of the relevant specific capacitances $\left(C_{s}\right)$ were calculated from the galvanostatic charge/discharge according to Equation (5) [57-59], and all of the details of the data are shown in Tables 3 and 4.

$$
C_{S}=\frac{i \times \Delta t}{m \times \Delta V}
$$

where $C_{s}$ is the specific capacitance $(\mathrm{F} / \mathrm{g}), i$ is the discharge current (A), $\Delta t$ is discharge time $(\mathrm{s}), m$ is the active mass of electrode $(\mathrm{g})$, and $\Delta V$ is the total potential deviation $(\mathrm{V})$.

It can be observed that the manganese dioxide-based nanocomposite materials exhibited the highest specific capacitance, and the specific capacitance of the mesoporous $\mathrm{MnO}_{2}$ that was tested in $\mathrm{KI}$ electrolyte was higher than that which was in $\mathrm{Na}_{2} \mathrm{SO}_{4}$ electrolyte. Besides, with the increase of the concentration of $\mathrm{I}^{-}$, the specific capacitance of the mesoporous $\mathrm{MnO}_{2}$ electrode material also increased accordingly. In addition, the mesoporous $\mathrm{MnO}_{2}$ showed a good ratio discharge property in $0.5 \mathrm{M} \mathrm{KI}$ electrolyte. In fact, the specific capacitance reached 205.5, 200.6 and $197.1 \mathrm{~F} / \mathrm{g}$ at $0.1,0.2$ and $0.5 \mathrm{~A} / \mathrm{g}$, respectively. This 
may be because of the effect of the electrical conductivity of the electrolyte. On the other hand, the specific capacitance of mesoporous $\mathrm{MnO}_{2}$ also changed when the blended with silver nanowires. However, according to the detailed data as shown in Table 4, the specific capacitance of mesoporous $\mathrm{MnO}_{2} /$ silver nanowires reached its maximum in $0.2 \mathrm{M} \mathrm{KI}$ electrolyte. This may be due to the synergistic effect of the electrical conductivity of the electrode and the electrolyte, the conductivity of the composite electrode and the ion activity of the electrolyte were worked together to the electrode materials, make sure that it has a good ratio discharge property under different test conditions [60,61]. Finally, the mesoporous $\mathrm{MnO}_{2}$ /silver nanowires show a good ratio discharge property in $0.2 \mathrm{M} \mathrm{KI}$ electrolyte, with the specific capacitance reaching to $208.1,200.5$ and $191.7 \mathrm{~F} / \mathrm{g}$ at $0.1,0.2$ and $0.5 \mathrm{~A} / \mathrm{g}$, respectively.

Table 3. The detail specific capacitance $(\mathrm{F} / \mathrm{g})$ of mesoporous $\mathrm{MnO}_{2}$ under different experimental conditions.

\begin{tabular}{ccccc}
\hline Sample & \multicolumn{4}{c}{ Mesoporous $\mathbf{M n O}_{2}$} \\
\hline Experimental Conditions & $0.1 \mathrm{M} \mathrm{KI}$ & $0.2 \mathrm{M} \mathrm{KI}$ & $0.5 \mathrm{M} \mathrm{KI}$ & $0.5 \mathrm{M} \mathrm{Na}_{2} \mathrm{SO}_{4}$ \\
\hline $0.1 \mathrm{~A} / \mathrm{g}$ & 106.6 & 229.2 & 205.5 & 200.3 \\
$0.2 \mathrm{~A} / \mathrm{g}$ & 89.3 & 152.5 & 200.6 & 85.72 \\
$0.5 \mathrm{~A} / \mathrm{g}$ & 57.1 & 152.9 & 197.1 & 49.12 \\
\hline
\end{tabular}

Table 4. The detail specific capacitance $(\mathrm{F} / \mathrm{g})$ of mesoporous $\mathrm{MnO}_{2} /$ silver nanowires under different experimental conditions.

\begin{tabular}{ccccc}
\hline Sample & \multicolumn{4}{c}{ Mesoporous MnO $/$ Silver Nanowires } \\
\hline Experimental Conditions & $0.1 \mathrm{M} \mathrm{KI}$ & $0.2 \mathrm{M} \mathrm{KI}$ & $0.5 \mathrm{M} \mathrm{KI}$ & $0.5 \mathrm{M} \mathrm{Na}_{2} \mathrm{SO}_{4}$ \\
\hline $0.1 \mathrm{~A} / \mathrm{g}$ & 152.1 & 208.1 & 158.1 & 187.2 \\
$0.2 \mathrm{~A} / \mathrm{g}$ & 130.8 & 200.5 & 133.7 & 150.2 \\
$0.5 \mathrm{~A} / \mathrm{g}$ & 117.2 & 191.7 & 115.8 & 113.1 \\
\hline
\end{tabular}

\section{Experimental Section}

\subsection{Preparation of Mesoporous $\mathrm{MnO}_{2}$}

First, $1.730 \mathrm{~g} \mathrm{KMnO}_{4}$ was dissolved in $100 \mathrm{~mL}$ of deionized water and stirred with a magnetic stirrer for $30 \mathrm{~min}$ to form a homogeneous solution at room temperature. Then, $2 \mathrm{~mL}$ concentrated sulfuric acid were added in $2.5 \mathrm{~mL}$ of ethylene glycol and aged for $20 \mathrm{~min}$ with stirring at ambient conditions. Then the mixture was poured into the above $\mathrm{KMnO}_{4}$ solution. The mixture was aged for 20 min with stirring at ambient conditions. The deposits were collected by centrifugation, washed several times with deionized water and absolute ethanol until the $\mathrm{pH}$ of the wash was neutral, and then dried at $60{ }^{\circ} \mathrm{C}$ overnight under air atmosphere. This sample was denoted as $\mathrm{MnO}_{2}-2$ for the following tests [25]. In the remaining three experiments, 4,5 and $7 \mathrm{~mL}$ concentrated sulfuric acid were added in the ethylene glycol solution, respectively, and the collected samples were correspondingly denoted as $\mathrm{MnO}_{2}-4, \mathrm{MnO}_{2}-5$ and $\mathrm{MnO}_{2}-7$ for the following tests. 


\subsection{Preparation of Silver Nanowires}

First, $5 \mathrm{~mL}$ of ethylene glycol was added to a disposable glass vial to which a stir bar was added; the vial was then suspended in an oil bath at $151.5^{\circ} \mathrm{C}$ and heated for $1 \mathrm{~h}$ under magnetic stirring. At the same time, reagent solutions were prepared. At $1 \mathrm{~h}$, a $\mathrm{Cu}$-additive solution was injected into the heated ethylene glycol. The solution was then heated for an additional $15 \mathrm{~min}$. $1.5 \mathrm{~mL}$ of a $0.147 \mathrm{M}$ polyvinylpyrrolidone solution in ethylene glycol, followed by $1.5 \mathrm{~mL}$ of a $0.094 \mathrm{M} \mathrm{AgNO}_{3}$ solution in ethylene glycol $[26,62]$. Then, the reaction was quenched by cooling the reaction vial in a room temperature water bath. Products were then washed with acetone and water.

\subsection{Preparation of Mesoporous Manganese Dioxide-Based Composite Materials}

Silver nanowires and mesoporous $\mathrm{MnO}_{2}$ were mixed directly with different molar ratios, and to reach the uniform by grinding.

\subsection{Material Characterization}

The Nitrogen adsorption-desorption isotherms were tested with a JW-BK Static Physisorption Analyzer. The BET surface area was calculated from the desorption branches in the relative pressure range of $0.05-0.35$, and the total pore volume and average pore diameter were evaluated at a relative pressure of about 0.99 . The materials were pretreated at $300{ }^{\circ} \mathrm{C}$ for $6 \mathrm{~h}$. Pore-size distributions (PSD) were calculated by Barrett-Joyner-Halenda $(\mathrm{BJH})$ plots using the nitrogen desorption isotherm. The pore width was obtained at the peak of the PSD curve. The morphologies of the prepared products were examined by scanning electron microscopy (SEM), using a FEI Quanta $400 \mathrm{~F}$ at $20 \mathrm{kV}$. X-ray diffraction (XRD) patterns were obtained with a Bruker D8 Diffractometer in reflection mode using $\mathrm{Cu} \mathrm{K} \alpha=0.154 \mathrm{~nm}$ with a voltage of $40 \mathrm{kV}$. In addition, Fourier transform infrared spectrometry (FT-IR) analyses were performed on a Thermal Nicolet Infrared Spectrometer.

\subsection{Preparation of Electrodes and Electrochemical Characterization}

The working electrodes were fabricated by the as-prepared materials, carbon black and poly tetrafluoroethylene (PTFE) at a weight ratio of 70:20:10. Typically, the mixture was formed to slurry by adding a few drops of 1-methyl-2-pyrrolidinone, then coated onto a stainless steel grid with an apparent area of $1 \mathrm{~cm} \times 1 \mathrm{~cm}$, and finally dried under air atmosphere at $70{ }^{\circ} \mathrm{C}$ for $2 \mathrm{~h}$. All electrochemical measurements were done in a three-electrode system. The prepared electrodes were impregnated with different aqueous electrolytes before the electrochemical tests for $0.5 \mathrm{~h}$ at room temperature. A Pt wire and an $\mathrm{Ag} / \mathrm{AgCl}$ cell were used as counter and reference electrodes, respectively. The $\mathrm{CV}$ and galvanostatic charge/discharge (GC) were measured by a CHI $660 \mathrm{C}$ electrochemical workstation. $\mathrm{CV}$ tests were performed between -0.3 and $0.7 \mathrm{~V}$. Galvanostatic charge/discharge curves were measured in the potential range of $-0.3-0.7 \mathrm{~V}$ at a current density of $0.5 \mathrm{~A} / \mathrm{g}$.

The conductivity tests were carried out according to Four Probes Tech type RTS-9. The ambient temperature of the experiments was in the range $23 \pm 5{ }^{\circ} \mathrm{C}$ and the operating humidity was in the range $73 \pm 5^{\circ} \mathrm{C}$. The samples were prepared with a typical diameter of around $13 \mathrm{~mm}$ and thick layer of around $0.5 \mathrm{~mm}$ by a tablet machine. 


\section{Conclusions}

In this study, uniform mesoporous $\mathrm{MnO}_{2}$ was obtained through a simple one-pot synthesis procedure at ambient temperature from $\mathrm{KMnO}_{4}$ and ethylene glycol under acidic conditions. Subsequently, the electrochemical performance of the resulting mesoporous $\mathrm{MnO}_{2}$-based electrode materials was tested in $\mathrm{KI}$ and $\mathrm{Na}_{2} \mathrm{SO}_{4}$ electrolytes. The mesoporous $\mathrm{MnO}_{2}$ showed a good ratio discharge properties in $0.5 \mathrm{M}$ $\mathrm{KI}$ electrolyte, the strength of the current was amplified 5 times (from 0.1 to $0.5 \mathrm{~A} / \mathrm{g}$ ), and the remain rate of the specific capacitance was $95 \%$ (from 205.5 down to $197.1 \mathrm{~F} / \mathrm{g}$ ). Due to the synergistic effect of the electrical conductivity of the electrode and the electrolyte, the mesoporous $\mathrm{MnO}_{2} /$ silver nanowires showed a good ratio discharge property in $0.2 \mathrm{M} \mathrm{KI}$ electrolyte, with the strength of the current being amplified five times (from 0.1 to $0.5 \mathrm{~A} / \mathrm{g}$ ), and the remain rate of specific capacitance at $92 \%$ (from 208.1 down to $191.7 \mathrm{~F} / \mathrm{g}$ ). The rate performance was also much higher than that in $\mathrm{Na}_{2} \mathrm{SO}_{4}$ electrolyte, where the remain rate were $25 \%$ (from 200.3 down to $49.1 \mathrm{~F} / \mathrm{g}$ ) and $60 \%$ (from 187.2 down to $113.1 \mathrm{~F} / \mathrm{g}$ ), respectively. Results indicate that KI electrolyte may become a new way for supercapacitors to change the specific capacitance.

\section{Acknowledgments}

The authors would like to acknowledge the support of the National Natural Science Foundation of China (NSFC, No. 21271031, No. 51063009 and No. 51203012), the Beijing Natural Science Foundation of China (No. 2092013, No. 2132009 and No. 2122015), the state key laboratory of organic-Inorganic composites, and the BIPT-support Project of Outstanding Professors and Management Experts (BIPT-POPME-2013).

\section{Author Contributions}

Xiuguo Cui and Yanhua Jiang conceived and designed the experiments; Yanhua Jiang, Zhongkai Hu, Yang Liu, Guangjian Xing and Jing Gan performed the experiments and analyzed the datas; Lei Zu, Huiqin Lian, Xiuguo Cui contributed the analysis tools; Yanhua Jiang wrote the paper.

\section{Conflicts of Interest}

The authors declare no conflict of interest.

\section{References}

1. Bhattacharjya, D.; Kim, M.-S.; Bae, T.-S.; Yu, J.-S. High performance supercapacitor prepared from hollow mesoporous carbon capsules with hierarchical nanoarchitecture. J. Power Sources 2013, 244, 799-805.

2. Tsay, K.-C.; Zhang, L.; Zhang, J. Effects of electrode layer composition/thickness and electrolyte concentration on both specific capacitance and energy density of supercapacitor. Electrochim. Acta 2012, 60, 428-436.

3. Burke, A. Ultracapacitors: Why, how, and where is the technology. J. Power Sources 2000, 91, $37-50$. 
4. Kötz, R.; Carlen, M. Principles and applications of electrochemical capacitors. Electrochim. Acta 2000, 45, 2483-2498.

5. Deshmukh, P.R.; Pusawale, S.N.; Jamadade, V.S.; Patil, U.M.; Lokhande, C.D. Microwave assisted chemical bath deposited polyaniline films for supercapacitor application. J. Alloys Compd. 2011, 509, 5064-5069.

6. Khosrozadeh, A.; Xing, M.; Wang, Q. A high-capacitance solid-state supercapacitor based on free-standing film of polyaniline and carbon particles. Appl. Energy 2015, 153, 87-93.

7. Karandikar, P.B.; Talange, D.B.; Mhaskar, U.P.; Bansal, R. Development, modeling and characterization of aqueous metal oxide based supercapacitor. Energy 2012, 40, 131-138.

8. Jiang, J.; Kucernak, A. Electrochemical supercapacitor material based on manganese oxide: Preparation and characterization. Electrochim. Acta 2002, 47, 2381-2386.

9. Yan, X.; Tong, X.; Wang, J.; Gong, C.; Zhang, M.; Liang, L. Synthesis of mesoporous NiO nanoflake array and its enhanced electrochemical performance for supercapacitor application. J. Alloys Compd. 2014, 593, 184-189.

10. Anothumakkool, B.; Kurungot, S. Electrochemically grown nanoporous $\mathrm{MnO}_{2}$ nanowalls on a porous carbon substrate with enhanced capacitance through faster ionic and electrical mobility. Chem. Commun. 2014, 50, 7188-7190.

11. Zhang, G.; Ren, L.; Deng, L.; Wang, J.; Kang, L.; Liu, Z.-H. Graphene-MnO2 nanocomposite for high-performance asymmetrical electrochemical capacitor. Mater. Res. Bull. 2014, 49, 577-583.

12. Liu, T.; Shao, G.; Ji, M.; Wang, G. Synthesis of $\mathrm{MnO}_{2}$-graphene composites with enhanced supercapacitive performance via pulse electrodeposition under supergravity field. J. Solid State Chem. 2014, 215, 160-166.

13. Li, Z.; Wang, J.; Liu, S.; Liu, X.; Yang, S. Synthesis of hydrothermally reduced graphene $/ \mathrm{MnO}_{2}$ composites and their electrochemical properties as supercapacitors. J. Power Sources 2011, 196, 8160-8165.

14. Wang, Q.; Plylahan, N.; Shelke, M.V.; Devarapalli, R.R.; Li, M.; Subramanian, P.; Djenizian, T.; Boukherroub, R.; Szunerits, S. Nanodiamond particles/reduced graphene oxide composites as efficient supercapacitor electrodes. Carbon 2014, 68, 175-184.

15. Chang, J.-K.; Lin, C.-T.; Tsai, W.-T. Manganese oxide/carbon composite electrodes for electrochemical capacitors. Electrochem. Commun. 2004, 6, 666-671.

16. Zhang, L.L.; Wei, T.; Wang, W.; Zhao, X.S. Manganese oxide-carbon composite as supercapacitor electrode materials. Micropor. Mesopor. Mat. 2009, 123, 260-267.

17. Zhang, J.; Shu, D.; Zhang, T.; Chen, H.; Zhao, H.; Wang, Y.; Sun, Z.; Tang, S.; Fang, X.; Cao, X. Capacitive properties of $\mathrm{PANI} / \mathrm{MnO}_{2}$ synthesized via simultaneous-oxidation route. J. Alloys Compd. 2012, 532, 1-9.

18. Kharade, P.M.; Chavan, S.G.; Salunkhe, D.J.; Joshi, P.B.; Mane, S.M.; Kulkarni, S.B. Synthesis and characterization of $\mathrm{PANI} / \mathrm{MnO}_{2}$ bi-layered electrode and its electrochemical supercapacitor properties. Mater. Res. Bull. 2014, 52, 37-41.

19. Yu, L.; Gan, M.; Ma, L.; Huang, H.; Hu, H.; Li, Y.; Tu, Y.; Ge, C.; Yang, F.; Yan, J. Facile synthesis of $\mathrm{MnO}_{2} /$ polyaniline nanorod arrays based on graphene and its electrochemical performance. Synth. Met. 2014, 198, 167-174. 
20. Yao, W.; Zhou, H.; Lu, Y. Synthesis and property of novel $\mathrm{MnO}_{2} @$ polypyrrole coaxial nanotubes as electrode material for supercapacitors. J. Power Sources 2013, 241, 359-366.

21. Wang, J.-G.; Yang, Y.; Huang, Z.-H.; Kang, F. $\mathrm{MnO}_{2} /$ polypyrrole nanotubular composites: Reactive template synthesis, characterization and application as superior electrode materials for high-performance supercapacitors. Electrochim. Acta 2014, 130, 642-649.

22. Zeng, Z.; Zhou, H.; Long, X.; Guo, E.; Wang, X. Electrodeposition of hierarchical manganese oxide on metal nanoparticles decorated nanoporous gold with enhanced supercapacitor performance. J. Alloys Compd. 2015, 632, 376-385.

23. Zhu, Y.; Liu, E.; Luo, Z.; Hu, T.; Liu, T.; Li, Z.; Zhao, Q. A hydroquinone redox electrolyte for polyaniline/ $\mathrm{SnO}_{2}$ supercapacitors. Electrochim. Acta 2014, 118, 106-111.

24. Roldán, S.; Granda, M.; Menéndez, R.; Santamaría, R.; Blanco, C. Supercapacitor modified with methylene blue as redox active electrolyte. Electrochim. Acta 2012, 83, 241-246.

25. Wang, Y.-T.; Lu, A.-H.; Li, W.-C. Mesoporous manganese dioxide prepared under acidic conditions as high performance electrode material for hybrid supercapacitors. Microporous Mesoporous Mater. 2012, 153, 247-253.

26. Zhang, Z.; Zheng, Y.; He, P.; Sun, Z. High yield preparation of silver nanowires by $\mathrm{CuCl}_{2}$-mediated polyol method and application in semitransparent conduction electrode. Phys. E 2011, 44, 535-540.

27. Amirjani, A.; Marashi, P.; Fatmehsari, D.H. Effect of $\mathrm{AgNO}_{3}$ addition rate on aspect ratio of $\mathrm{CuCl}_{2}$-mediated synthesized silver nanowires using response surface methodology. Colloid Surface A 2014, 444, 33-39.

28. Wei, Y.; Chen, S.; Li, F.; Liu, K.; Liu, L. Hybrids of silver nanowires and silica nanoparticles as morphology controlled conductive filler applied in flexible conductive nanocomposites. Compos. A 2015, 73, 195-203.

29. Reddy, R.N.; Reddy, R.G. Sol-gel $\mathrm{MnO}_{2}$ as an electrode material for electrochemical capacitors. J. Power Sources 2003, 124, 330-337.

30. Tang, N.; Tian, X.; Yang, C.; Pi, Z. Facile synthesis of $\alpha-\mathrm{MnO}_{2}$ nanostructures for supercapacitors. Mater. Res. Bull. 2009, 44, 2062-2067.

31. Yu, P.; Zhang, X.; Chen, Y.; Ma, Y. Self-template route to $\mathrm{MnO}_{2}$ hollow structures for supercapacitors. Mater. Lett. 2010, 64, 1480-1482.

32. Zhang, H.; Wang, Y.; Wang, C. Influence of surfactant on the capacitive performance of manganese dioxide prepared at different temperatures. Energy Convers. Manag. 2013, 74, 286-292.

33. Jiang, R.; Huang, T.; Liu, J.; Zhuang, J.; Yu, A. A novel method to prepare nanostructured manganese dioxide and its electrochemical properties as a supercapacitor electrode. Electrochim. Acta 2009, 54, 3047-3052.

34. Zhang, H.; Wang, Y.; Liu, C.; Jiang, H. Influence of surfactant CTAB on the electrochemical performance of manganese dioxide used as supercapacitor electrode material. J. Alloys Compd. 2012, 517, 1-8.

35. Li, S.; Qi, L.; Lu, L.; Wang, H. Cotton-assisted preparation of mesoporous manganese oxide for supercapacitors. RSC Adv. 2012, 2, 6741-6743.

36. Rusi, S.R.M. Synthesis of $\mathrm{MnO}_{2}$ particles under slow cooling process and their capacitive performances. Mater. Lett. 2013, 108, 69-71. 
37. Wang, H.-Q.; Yang, G.-F.; Li, Q.-Y.; Zhong, X.-X.; Wang, F.-P.; Li, Z.-S.; Li, Y.-H. Porous nano- $\mathrm{MnO}_{2}$ : Large scale synthesis via a facile quick-redox procedure and application in a supercapacitor. New J. Chem. 2011, 35, 469-475.

38. Li, S.; Wang, X.; Shen, C.; Wang, J.; Kang, F. Nanostructured manganese dioxides as active materials for micro-supercapacitors. Micro Nano Lett. 2012, 7, 744-748.

39. Subramanian, V.; Zhu, H.; Wei, B. Alcohol-assisted room temperature synthesis of different nanostructured manganese oxides and their pseudocapacitance properties in neutral electrolyte. Chem. Phys. Lett. 2008, 453, 242-249.

40. Lee, H.Y.; Goodenough, J.B. Supercapacitor Behavior with KCl Electrolyte. J. Solid State Chem. 1999, 144, 220-223.

41. Kundu, M.; Liu, L. Direct growth of mesoporous $\mathrm{MnO}_{2}$ nanosheet arrays on nickel foam current collectors for high-performance pseudocapacitors. J. Power Sources 2013, 243, 676-681.

42. Ming, B.; Li, J.; Kang, F.; Pang, G.; Zhang, Y.; Chen, L.; Xu, J.; Wang, X. Microwave-hydrothermal synthesis of birnessite-type $\mathrm{MnO}_{2}$ nanospheres as supercapacitor electrode materials. J. Power Sources 2012, 198, 428-431.

43. Zhao, Y.; Jiang, P.; Xie, S.-S. ZnO-template-mediated synthesis of three-dimensional coral-like $\mathrm{MnO}_{2}$ nanostructure for supercapacitors. J. Power Sources 2013, 239, 393-398.

44. Babakhani, B.; Ivey, D.G. Effect of electrodeposition conditions on the electrochemical capacitive behavior of synthesized manganese oxide electrodes. J. Power Sources 2011, 196, 10762-10774.

45. Chou, S.; Cheng, F.; Chen, J. Electrodeposition synthesis and electrochemical properties of nanostructured $\gamma-\mathrm{MnO}_{2}$ films. J. Power Sources 2006, 162, 727-734.

46. Yan, J.; Wei, T.; Cheng, J.; Fan, Z.; Zhang, M. Preparation and electrochemical properties of lamellar $\mathrm{MnO}_{2}$ for supercapacitors. Mater. Res. Bull. 2010, 45, 210-215.

47. Song, Z.; Liu, W.; Zhao, M.; Zhang, Y.; Liu, G.; Yu, C.; Qiu, J. A facile template-free synthesis of $\alpha-\mathrm{MnO}_{2}$ nanorods for supercapacitor. J. Alloys Compd. 2013, 560, 151-155.

48. Yang, Y.-J.; Liu, E.-H.; Li, L.-M.; Huang, Z.-Z.; Shen, H.-J.; Xiang, X.-X. Nanostructured amorphous $\mathrm{MnO}_{2}$ prepared by reaction of $\mathrm{KMnO}_{4}$ with triethanolamine. J. Alloys Compd. 2010, $505,555-559$.

49. Senthilkumar, S.T.; Selvan, R.K.; Melo, J.S. Redox additive/active electrolytes: A novel approach to enhance the performance of supercapacitors. J. Mater. Chem. A 2013, 1, 12386-12394.

50. Senthilkumar, S.T.; Selvan, R.K.; Lee, Y.S.; Melo, J.S. Electric double layer capacitor and its improved specific capacitance using redox additive electrolyte. J. Mater. Chem. A 2013, 1, 1086-1095.

51. Lee, Y.W.; Do, K.; Lee, T.H.; Jeon, S.S.; Yoon, W.J.; Kim, C.; Ko, J.; Im, S.S. Iodine vapor doped polyaniline nanoparticles counter electrodes for dye-sensitized solar cells. Synth. Met. 2013, 174, 6-13.

52. Wan, C.; Yuan, L.; Ye, X.; Wu, F. Silver chloride micelle-induced tuning of pseudocapacitive manganese dioxide. Electrochim. Acta 2014, 147, 712-719.

53. Huang, Z.; Zhang, M.; Cheng, J.; Gong, Y.; Li, X.; Chi, B.; Pu, J.; Jian, L. Silver decorated beta-manganese oxide nanorods as an effective cathode electrocatalyst for rechargeable lithium-oxygen battery. J. Alloys Compd. 2015, 626, 173-179. 
54. Wu, X.M.; He, Z.Q.; Chen, S.; Ma, M.Y.; Xiao, Z.B.; Liu, J.B. Silver-doped lithium manganese oxide thin films prepared by solution deposition. Mater. Lett. 2006, 60, 2497-2500.

55. Gamby, J.; Taberna, P.L.; Simon, P.; Fauvarque, J.F.; Chesneau, M. Studies and characterisations of various activated carbons used for carbon/carbon supercapacitors. J. Power Sources 2001, 101, 109-116.

56. Zhu, J.-J.; Yu, L.-L.; Zhao, J.-T. 3D network mesoporous beta-manganese dioxide: Template-free synthesis and supercapacitive performance. J. Power Sources 2014, 270, 411-417.

57. Zeng, Z.; Long, X.; Zhou, H.; Guo, E.; Wang, X.; Hu, Z. On-chip interdigitated supercapacitor based on nano-porous gold/manganese oxide nanowires hybrid electrode. Electrochim. Acta 2015, 163, 107-115.

58. Khomenko, V.; Raymundo-Piñero, E.; Béguin, F. Optimisation of an asymmetric manganese oxide/activated carbon capacitor working at $2 \mathrm{~V}$ in aqueous medium. J. Power Sources 2006, 153, 183-190.

59. Yousefi, T.; Davarkhah, R.; Golikand, A.N.; Mashhadizadeh, M.H. Synthesis, characterization, and supercapacitor studies of manganese (IV) oxide nanowires. Mater. Sci. Semicond. Process. 2013, $16,868-876$.

60. Wang, K.; Zhao, C.; Min, S.; Qian, X. Facile Synthesis of $\mathrm{Cu}_{2} \mathrm{O} / \mathrm{RGO} / \mathrm{Ni}(\mathrm{OH})_{2}$ Nanocomposite and Its Double Synergistic Effect on Supercapacitor Performance. Electrochim. Acta 2015, 165, 314-322.

61. Gong, H.; Wang, X.; Zhang, S.; Li, L. Synergistic effect of rare-earth elements on the dielectric properties and reliability of batio3-based ceramics for multilayer ceramic capacitors. Mater. Res. Bull. 2016, 73, 233-239.

62. Korte, K.E.; Skrabalak, S.E.; Xia, Y. Rapid synthesis of silver nanowires through a CuCl- or $\mathrm{CuCl}_{2}$-mediated polyol process. J. Mater. Chem. 2008, 18, 437-441.

(C) 2015 by the authors; licensee MDPI, Basel, Switzerland. This article is an open access article distributed under the terms and conditions of the Creative Commons Attribution license (http://creativecommons.org/licenses/by/4.0/). 